\title{
PROJOVEM URBANO: ESTRATÉGIA EDUCACIONAL PARA REDUÇÃO DA POBREZA NOS GOVERNOS LULA DA SILVA E DILMA ROUSSEFF?
}

\author{
Carlos Soares Barbosa \\ Universidade do Estado do Rio de Janeiro (UERJ), Rio de Janeiro, Rio \\ de Janeiro, Brasil
}

\begin{abstract}
RESUMO: O artigo visa a analisar o alinhamento das ações comunitárias estimuladas no ProJovem Urbano (PJU), ao papel atribuído à educação no novo milênio, o de produzir capital social como estratégia para redução da pobreza e das desigualdades sociais. A pesquisa documental-empírica foi desenvolvida no município de Mesquita/RJ e fundamentada no pensamento histórico-crítico. Com base na análise dos relatórios das agências multilaterais, observação das aulas e entrevistas realizadas com professores, conclui-se que o PJU se configura como estratégia de governabilidade, a serviço da "administração" da pobreza. Sem muito explorar politicamente as ações comunitárias, os professores acabam por fortalecer a "união dos esforços" para que os problemas sociais se mantenham no patamar sustentável e não atrapalhem os interesses do grande capital.
\end{abstract}

Palavras-chave: ProJovem Urbano. Pobreza. Capital social. Jovens.

Introdução

Percorridas quase duas décadas do novo milênio, a preocupação com o crescimento da pobreza e das desigualdades sociais continua a ser um dilema para o capital, uma vez que elas desvelam o caráter expropriador e explorador do capital sobre o trabalho e exigem ações de ajustes e reformas em diversas áreas que visem à garantia da governabilidade e à reprodução do sistema capitalista neoliberal. Devido à crise da sociedade salarial e à não garantia do pleno emprego, configura entre os ajustes o novo papel atribuído à educação, de não só produzir capital humano, mas também capital social. Por capital social entende-se a capacidade das pessoas trabalharem juntas visando a objetivos comuns em grupos e organizações. Para Coleman (1988) e Putnam (2002), essa capacidade de associação é uma porção distinta do capital humano e depende do grau em que as comunidades compartilham normas e valores e se mostram dispostas a subordinarem interesses individuais aos de grupos maiores.

Nas últimas três décadas a produção de capital social tem sido recomendada como parte das estratégias para a redução da pobreza e da desigualdade social, materializada pela promoção da solidariedade entre os indivíduos e o resgate da cultura cívica e dos valores de cooperação. Fukuyama $(2005)$ e Kliksberg $(1998,2003)$ defendem que as questões sociais podem ser resolvidas caso as pessoas aprendam a trabalhar 
juntas em benefício de interesses coletivos, fazendo da participação uma poderosa estratégia para a resolução dos problemas locais. Tais orientações são defendidas por Amartya Sen, ganhador do Prêmio Nobel de economia, em 1998, por introduzir na ciência econômica a "dimensão ética" e a "preocupação com os pobres", além de constarem nos relatórios das agências multilaterais - Banco Mundial, Bid, ONU e suas unidades Unesco e Cepal -, no Projeto da "Terceira Via" (GIDDENS, 2005), assim como nas Políticas de Desenvolvimento do Milênio, elaboradas durante o encontro da "Cúpula do Milênio da Organização das Nações Unidas", realizado em Nova York, no ano 2000, das quais o Brasil foi signatário.

Os "Objetivos de Desenvolvimento do Milênio", expressos na Declaração do Milênio das Nações Unidas, estabeleciam um compromisso compartilhado entre as Nações para o desenvolvimento humano sustentável. De acordo com o referido documento, a produção de capital social é considerada estratégia fundamental para reduzir a pobreza, que é responsabilidade tanto do Estado quanto da sociedade civil. Às organizações da sociedade civil cabem a função de formar redes solidárias para atenuar os efeitos da ineficiência gestora do Estado e das políticas econômicas neoliberais, enquanto ao Estado cabe fomentar os valores do capital social nos membros de uma comunidade através de programas educacionais e sociais. Esse foi um dos objetivos da década da "Educação para o Desenvolvimento Sustentável" (2005-2015) coordenada pela Unesco (2005), que passou a englobar, para compreensão de "desenvolvimento sustentável", os fatores socioculturais e as questões sociopolíticas de igualdade, pobreza, democracia e qualidade de vida.

No Brasil, o combate à pobreza foi o "carro-chefe" das políticas sociais implementadas no governo Lula. Além de ampliar as políticas de transferência de renda para os setores mais pobres, como o Programa Fome Zero e o Bolsa Família, promoveu a recuperação expressiva do poder de compra do salário mínimo, a popularização do crédito para os segmentos anteriormente excluídos, conjugado com a criação de programas de construção de moradias populares e a ampliação da democratização das oportunidades educacionais aos segmentos empobrecidos da população. Este foi o contexto do Programa Nacional de Inclusão de Jovens: Educação Básica, Qualificação Profissional e Ação Comunitária - ProJovem -, criado em 2005. Por meio do recurso discursivo do protagonismo juvenil, a participação cidadã é uma das dimensões do currículo, à qual se reserva parte da carga horária para ações de "serviço social voluntário" e/ou ações comunitárias. Em 2008 o programa sofreu algumas modificações e passou a ser denominado ProJovem Urbano (PJU). No início do governo Dilma Roussef, em 2011, novas alterações foram empreendidas, entre elas, sua inserção no conjunto das ações da Secretaria de Educação Continuada, Alfabetização, Diversidade e Inclusão, do Ministério da Educação (SECADI/MEC), onde permanece até o momento, no governo de Michel Temer.

O PJU é executado por meio da parceria com estados e municípios, com o objetivo de proporcionar aos jovens de 18 a 29 anos, em um prazo de 18 meses, a conclusão do ensino fundamental, iniciação à informática, qualificação profissional inicial e a participação em ações coletivas e de interesse público. Desde sua criação o 
programa tem sido objeto de estudo de diversos campos de investigação, a partir de diferentes matrizes teóricas e metodológicas. Entretanto, são poucos os estudos que o contextualiza ao projeto "novo desenvolvimentista" e enquanto ação da política social de combate à pobreza, recomendada pelos organismos internacionais ligados organicamente aos interesses do capital. E como a pobreza agora é entendida de forma mais ampla, "como a incapacidade de alcançar os padrões básicos em nutrição, saúde, educação, meio ambiente e participação" (BANCO MUNDIAL, 2000, p. 12), dar voz aos pobres, estimular sua participação na resolução dos problemas sociais locais e promover processos de escolarização e qualificação profissional, com o intuito de aproveitar a "vocação produtiva" das comunidades e evitar desperdício dos recursos humanos potencialmente produtivos, são algumas das orientações feitas aos países em desenvolvimento pelas agências multilaterais no início do novo milênio (BANCO MUNDIAL, 2004; CEPAL, 2000).

Neste sentido, compreendemos o PJU como um braço da política de combate (leia-se: alívio) à pobreza instituída nos governos Lula da Silva e Dilma Roussef. Integra os demais programas de distribuição de renda e de ampliação da oferta de oportunidades aos que estiveram até então fora do alcance do raio de ação das políticas públicas. Assim, o presente texto visa a identificar o alinhamento do desenho curricular e os objetivos do PJU com o novo papel atribuído à educação no novo milênio, bem como perceber a compreensão dos professores em relação às ações comunitárias estimuladas no programa enquanto estratégia para redução da pobreza e da desigualdade social. É uma vertente da pesquisa documental-empírica, de abordagem qualitativa, realizada durante os anos de 2015-2016 no município de Mesquita, localizado na Baixada Fluminense do Estado do Rio de Janeiro, fundamentada nos teóricos do pensamento histórico-crítico, tendo utilizado, metodologicamente, da análise dos documentos das agências multilaterais produzidos no contexto de origem do PJU, conjugado à observação das aulas e entrevistas com roteiros semiestruturados realizadas com oito professores, do total de treze participantes do programa. A seleção dos sujeitos pautouse na participação espontânea à pesquisa, tendo privilegiado a educadora de "Participação Cidadã" por ser responsável pela coordenação do Plano de Ação Comunitária (PLA), elaborado e executado pelos estudantes.

Cabe ressaltar que a identificação dos nexos entre as recomendações dos organismos internacionais e o PJU não se fundamentam, de nossa parte, na compreensão dicotômica de "imposição" e "subserviência pacífica" dos países de capitalismo central aos países periféricos ou semiperiféricos, como o Brasil, mas por entender que nossa fonte de estabilidade econômica e política reside na convergência entre os interesses internos e externos - condição específica do capitalismo dependente brasileiro (FERNANDES, 1975). Convergência esta, ainda segundo o autor, que impede rupturas definitivas com o passado e ocasiona a permanência do desenvolvimento desigual e combinado. É nessa perspectiva que entendemos o projeto "novo desenvolvimentista" do governo Lula da Silva, pois, ao mesmo tempo em que manteve a hegemonia do capital financeiro no "bloco histórico" de sustentação de seu governo, não alterou o status quo das burguesias nacionais de sócias minoritárias das burguesias internacionais. 
Para cumprimento do objetivo aqui proposto, num primeiro momento contextualizaremos o PJU no âmbito das demais políticas de redução da pobreza e de sua importância para o projeto "novo-desenvolvimentista". Em seguida, identificaremos o alinhamento entre os objetivos do programa, as ações comunitárias e o papel atribuído à educação no novo milênio, de produzir capital social como estratégia para redução da pobreza e das desigualdades sociais, conforme orientação expressa nos relatórios das agências multilaterais. Por fim analisaremos a concepção dos educadores em relação à Participação Cidadã, bem como as ações planejadas/executadas pelos jovens e contidas no Plano de Ação Comunitária (PLA), apontando sua intencionalidade, potencialidade e limitações.

\section{PROJOVEM URBANO: EIXO DO PROJETO NOVO DESENVOLVIMENTISTA}

Em síntese, o projeto "novo-desenvolvimentista" dos governos Lula da Silva e Dilma Roussef pode ser compreendido como o período de crescimento econômico conjugado à melhor distribuição de renda. Isso só foi possível após a reformulação do Estado, que de "mínimo" - como defendido pela ortodoxia neoliberal e defendido nos governo de Fernando Henrique Cardoso - passou a ter maior intervenção na economia e dar maior atenção às questões sociais, concebido como regulador e coordenador de processos de desenvolvimento econômico e social por meio de parcerias com o empresariado (CASTELO, 2010).

O projeto "novo-desenvolvimentista" diferencia-se do modelo desenvolvimentista adotado no Brasil nas décadas de 1950-1970. Este, embora tenha incorporado em alguns períodos as massas urbanas ao processo produtivo e ao sistema político, mas, por não possuir uma política social consistente, não foi suficiente para retirar a maioria da população brasileira da exclusão dos processos da "modernização" e industrialização. $O$ "novo desenvolvimentismo", por sua vez, conjugou desenvolvimento econômico e desenvolvimento social, aliando crescimento econômico, distribuição de renda, redução significativa da pobreza e incorporação dos excluídos no mercado de consumo (BRAGA, 2012). Apesar do avanço das políticas sociais, o novo padrão de desenvolvimento eximiu de confrontar o modo capitalista neoliberal, que teve continuidade com novos contornos e feições, ocasionando a configuração de uma nova sociabilidade capitalista. Para conformar os trabalhadores a essa nova sociabilidade, a educação tem importante papel a cumprir, inclusive o ProJovem.

Criado originalmente em conjunto a outros programas educacionais e de qualificação profissional, como o ProUni, o Escola de Fábrica e o Programa Nacional de Estímulo ao Primeiro Emprego, a meta do ProJovem era atender, no período de 2005 a 2008, 200.000 jovens de todas as capitais brasileiras e Distrito Federal que tivessem terminado $\circ 5^{\circ}$ ano, mas não concluído o $9^{\circ}$ ano do Ensino Fundamental. Para isso, já no seu primeiro ano de existência contou com $\mathrm{R} \$ 300$ milhões garantidos no Orçamento da União. Em 2006, o programa ampliou o atendimento para os municípios das regiões metropolitanas que possuíam 200.000 habitantes ou mais, tendo recebido a adesão de 29 cidades. Como já mencionado, em 2008 o programa sofreu algumas modificações, 
passando a se chamar ProJovem Urbano. Além da mudança do nome, seu público-alvo passou a abarcar jovens com até 29 anos, a duração do programa foi ampliada de 12 para 18 meses, seu funcionamento passou a ser obrigatório em escolas públicas e a denominação da área do conhecimento foi alterada de "Ação Comunitária" para "Participação Cidadã". A meta era atender 763.930 jovens, assim distribuídos: 332.380 em 2008; 254.725 em 2009; e 176.825 em 2010 (FÉRES, 2008).

Por meio da gestão compartilhada entre os entes federativos, a gestão local é de responsabilidade das prefeituras (nas cidades com mais de 200 mil habitantes) ou do estado (nas cidades com menos de 200 mil habitantes). Cabe aos municípios e estados criar as estruturas necessárias para operacionalização do PJU, entre as quais realizar a matrícula dos jovens e selecionar os profissionais e as escolas que atenderão o programa. Ao governo federal cabe a produção e distribuição do livro didático, pagamento dos profissionais e da bolsa-auxílio mensal aos estudantes no valor de cem reais, sob a condição de $75 \%$ de frequência, e a entrega dos trabalhos escolares.

\section{PARTICIPAÇÃO CIDADÂ E AS ESTRATÉGIAS PARA REDUÇÃO DA POBREZA}

Até o golpe desferido em 2016, que culminou com o impeachment da presidente Dilma Roussef, o PJU caminhava para se consolidar como significativo processo formativo na escolarização de jovens, ancorado na proposta de formação integral que se operava na aliança entre teoria e prática e no reconhecimento da dimensão educativa do trabalho e da participação cidadã. Visando à formação integral dos jovens e ancorado na interdisciplinaridade, a matriz curricular proporciona o estudo das disciplinas da etapa do Ensino Fundamental (Língua Portuguesa, Ciências Humanas, Ciências da Natureza, Matemática e Língua Inglesa), como também iniciação em Informática, atividades inclusivas com base em temas integradores e aula de Qualificação Profissional inicial e de Participação Cidadã.

A área do conhecimento denominada "Participação Cidadã" foi pensada com base no binômio cidadania e solidariedade. Tem como referência a "nova concepção de assistência social que redefine os direitos à proteção social e à participação social, e a política dos jovens como via de construção de protagonismo e autonomia" (BRASIL, 2005, p.18). Assim como define a nova Política Nacional de Assistência Social (PNAS), a "Participação Cidadã" fundamenta-se no princípio de que a promoção da convivência social realiza-se por meio de atividades socioeducativas que visam a desenvolver capacidade, fortalecer laços e vínculos sociais de pertencimento para que os cidadãos construam autonomia, sustentabilidade, protagonismo social e reconheçam seus direitos e deveres de cidadania (BRASIL, 2004). Neste sentido, os formuladores do PJU acreditam que "a força de combinação desses dois termos - "social" e "educativa" - está na finalidade socioeducativa de criar situações de aprendizagens capazes de ampliar a participação e multiplicar as possibilidades de convivência dos jovens." (BRASIL, 2008, p. 37). A partir desses princípios entende-se a razão de a disciplina ser ministrada preferencialmente por profissional com formação superior em Serviço Social.

Com carga horária total de 78 horas a "Participação Cidadã é composta por dois conjuntos de atividades. No primeiro, são focalizados conceitos básicos para o fomento à participação, momento em que se discute questões referentes aos direitos humanos, 
direitos do consumidor, acesso aos bens e serviços públicos, ética e cidadania, questões de saneamento, saúde pública, qualidade e acessibilidade dos serviços, preservação do meio ambiente, violência, drogas, sexualidade, participação social, direito à cultura e ao lazer, entre outros. O objetivo desse primeiro conjunto de atividades é "sensibilizar o jovem para os problemas sociais de sua comunidade, estimulando-o a assumir atitude pró-ativa e mobilizando-o para participação cidadã" (BRASIL, 2005, p. 121).

O segundo conjunto das atividades consiste no Plano de Ação Comunitária (PLA) que, em síntese, trata-se do planejamento, realização, avaliação e sistematização de uma ação social escolhida pelos estudantes a partir do conhecimento de sua realidade próxima. As ações comunitárias, embora estejam sob a coordenação da educadora de Participação Cidadã, contam com a participação dos educadores das demais dimensões do currículo por entender que "participar e exercer cidadania são ações que se aprendem fazendo" (BRASIL, 2008, p. 44),

A elaboração do PLA inicia-se pelo mapeamento de oportunidades de engajamento social na comunidade, identificando as organizações, movimentos sociais, comunitários, juvenis, programas da rede pública socioassistencial, de saúde, de educação e de cultura existentes localmente. Em seguida, através de trabalho de campo, os jovens realizam um breve diagnóstico social, identificando os principais problemas da comunidade em que estão inseridos para, posteriormente, escolher o desafio para o qual irão planejar uma intervenção coletiva.

Escolhido o desafio a ser enfrentado, o próximo passo consiste na elaboração propriamente das ações. $O$ propósito é fazer com que os jovens percebam a importância do planejamento para a realização das mudanças que desejam fazer. Para isso, é preciso que haja no PLA a descrição detalhada das ações e os responsáveis por cada ação. Para os formuladores do programa, o PLA é uma ferramenta importante para tornar organizada a atuação dos jovens e para que haja mais possibilidades de sucesso, uma vez que "planejamos para construir o futuro, traçando o caminho entre o momento presente e o que queremos alcançar com a nossa ação" (BRASIL, 2008, p. 102). A execução das ações planejadas é a etapa mais importante do PLA e é a etapa final reservada para avaliação/sistematização de todo o processo percorrido, a fim de se extrair as lições adquiridas por essa experiência coletiva de intervenção social.

Os elaboradores do programa acreditam que a avaliação da realidade e a sistematização dos trabalhos nos planos de ação comunitária contribuem para os jovens "compreender a eficácia do trabalho coletivo e solidário ao vivenciar situações de conflito e negociações para sua superação, dimensionar conquistas, avanços e recuos" (BRASIL, 2008, p. 23). Ao refletir sobre as práticas sociais e consolidar suas experiências, desenvolvem competências e habilidades necessárias à participação social e ao exercício da cidadania. Assim, ao final de todas as etapas, espera-se que os jovens concluintes do programa sejam capazes de:

[...] assumir responsabilidades em relação ao seu grupo familiar e à sua comunidade, assim como frente aos problemas que afetam o país, a sociedade global e o planeta; identificar problemas e necessidades de sua comunidade, planejar iniciativas concretas visando a sua superação e participar da respectiva 
BARBOSA, C. S

implementação e avaliação; conviver e trabalhar em grupo, valorizando a diversidade de opiniões e a resolução negociada de conflitos; exercitar valores de solidariedade e cooperação, posicionando-se ativamente contra qualquer forma de racismo e discriminação; exercer direitos e deveres da cidadania, participar de processos e instituições que caracterizam a vida pública numa sociedade democrática (BRASIL, 2008, p.38).

Com base em tais objetivos, verifica-se $o$ alinhamento das ações comunitárias estimuladas no PJU ao papel atribuído à educação no novo milênio, o de produzir capital social com base nos valores de solidariedade, cooperação e responsabilidade social como estratégia para redução da pobreza e das desigualdades sociais. Os relatórios das agências multilaterais incentivam os países em desenvolvimento a criarem programas educacionais que estimulem a construção desses valores nos jovens, por meio de iniciativas concretas ou de serviço voluntário, com vista à superação dos problemas locais. Essa proposta já se encontra presente na origem do ProJovem ao explicitar os objetivos da ação comunitária:

desenvolver capacidades; proporcionar vivências solidárias, cooperativas e cidadãs; desenvolver a capacidade de trabalho coletivo e de lidar com a adversidade, a diferença e o conflito; para que o jovem construa autonomia, sustentabilidade, protagonismo social e reconheça seus direitos e deveres de cidadania (BRASIL, 2005).

A Comissão Econômica para América Latina e Caribe (CEPAL) destaca o papel da educação no combate à pobreza e nos processos de redução das desigualdades sociais e de inclusão social, defendendo a reforma intelectual e moral com atuação direta nas esferas microssociais e individuais para o enfrentamento da questão social (CEPAL, 2000). Para os cepalinos, os programas educacionais, a partir de novas bases curriculares e novas formas de gestão, devem promover maior relação com a comunidade, não se furtando à formação de dirigentes e à capacitação dos pobres para participação comunitária, entendida como:

organização racional, consciente e voluntária dos habitantes de determinado espaço, com o objetivo de propor iniciativas que satisfaçam suas necessidades, definir interesses e valores comuns, colaborar na realização de obras e na prestação de serviços públicos, e influir na tomada de decisões dos grupos de poder dentro desse espaço (CEPAL, 2007, p. 56).

Compreendendo a pobreza de forma mais ampla, deve-se atacá-la por meio de ações para além do terreno econômico, já que "pobreza é mais que renda ou desenvolvimento humano inadequados; é também vulnerabilidade e falta de voz, de poder e representação" (BANCO MUNDIAL, 2000, p.12). Assim, para o Banco Mundial, dar direito de voz e (suposto) poder aos pobres na sociedade é duplamente estratégico: garante a governabilidade, incide em maior cooperação na resolução dos problemas locais e ajuda os mais necessitados. De acordo com este pensamento, as questões sociais podem ser resolvidas no âmbito da sociedade civil por meio da solidariedade dos indivíduos, reduzindo assim a responsabilidade do Estado e incidindo na continuidade 
de Estado "mínimo", porém forte, como defendem Fukuyama (2005) e Bresser Pereira (2006).

Por ser o capital social a base ideológica das políticas de desenvolvimento do milênio, o financiamento de projetos e programas voltados para elevação do nível de instrução (básico) e capacitação dos pobres nas decisões comunitárias são ações importantes para a "administração" da pobreza em níveis sustentáveis, sem que os múltiplos aspectos da pobreza coloquem em risco o projeto de acumulação da riqueza em execução no país. Conceitualmente, o ProJovem Urbano cumpre essa demanda requerida à "Educação para o Desenvolvimento Sustentável" (UNESCO, 2005), pois, além do aumento da escolaridade, as diretrizes operacionais ressaltam que deve:

incluir no percurso formativo situações pedagógicas que propiciem a aprendizagem de trabalho coletivo, de práticas associativas, de ações reivindicativas e propositivas que contribuam para a construção da participação cidadã dos jovens e que fomentem o exercício da democracia, da solidariedade, da cooperação (BRASIL, 2008, p. 39).

\section{INTENCIONALIDADE, POTENCIALIDADE E LIMITES DAS AÇÕES COMUNITÁRIAS}

A pesquisa centrou-se em duas escolas da rede municipal de Mesquita onde o programa foi executado, conforme parceria firmada entre os governos federal e municipal. Para atender às quatro turmas existentes no horário noturno - duas em cada escola -, treze professores foram contratados pela Secretaria Municipal de Educação de Mesquita de modo a viabilizar as disciplinas presentes na matriz curricular. A professora de Participação Cidadã era a única que atendia a duas unidades escolares, uma vez que possuía menor carga horária, de apenas uma hora semanal em cada turma.

Questionados se participavam de alguma instituição e/ou organização social de interesse coletivo todos afirmaram não participar, o que foi justificado pela professora de Ciências da Natureza pela "necessidade de trabalharem longas jornadas para garantir o sustento e a razoável qualidade de vida para si e sua família". Decerto, como destaca Martorano (2011), a garantia de trabalho que permita a satisfação das necessidades humanas mais elementares interfere no interesse pela política, o que é intensificado por relativo ceticismo que professores possuem com relação às instituições políticas, como sindicatos, partidos, conselhos e órgãos pertencentes aos poderes legislativos e executivos. A exceção foi a professora de Participação Cidadã, que, por ser formada em Serviço Social, enfatiza a importância de ações que empoderem as classes trabalhadoras para maior participação, seja nos espaços políticos institucionalizados ou não.

Para os objetivos da pesquisa, buscamos perceber a concepção que os educadores possuíam sobre a disciplina Participação Cidadã. Considerando a unidade existente entre a forma de compreender o mundo e a maneira de agir sobre ele, embora não seja uma relação destituída de contradição, a compreensão que professores possuem sobre participação, cidadania e a obrigatoriedade dos jovens do PJU de realizar ações comunitárias são mediações que podem nos levar a melhor compreender o sentido de suas práticas pedagógicas. 
Na concepção dos professores, a Participação Cidadã e o desenvolvimento de ações comunitárias são aspectos que tornam o currículo do PJU inovador, diferenciando-o de outros programas educacionais destinados ao segmento juvenil. Para eles, ao dialogar com outras áreas do conhecimento, a Participação Cidadã ajuda os jovens a:

\begin{abstract}
Se conscientizarem de sua importância como ser atuante na sociedade, capaz de modificar seu meio em benefícios de todos. No entanto, os conhecimentos que podem proporcionar a participação cidadã dos jovens devem ser discutidos em todas as disciplinas e não apenas em uma disciplina específica (PROFESSORA DE LINGUA PORTUGUESA, 2016).

[...] deixarem a condição de meros receptores das ações públicas para tornarem sujeitos de mudanças. A perceberem que o exercício da cidadania vai muito além de um voto dado a cada quatro anos; traz a compreensão que cidadania deve ser parte do nosso dia a dia (PROFESSORA DE PARTICIPAÇÃO CIDADÃ, 2016).
\end{abstract}

A importância que professores conferem à Participação Cidadã converge com a proposta de protagonismo juvenil expressa no projeto pedagógico do programa, isto é, na compreensão do jovem enquanto ser político cuja ação participativa pode gerar mudanças decisivas na realidade social, ambiental, política e cultural. Daí, na concepção da professora de Participação Cidadã, a importância da prática educativa de todos os docentes em levar os jovens a abandonarem a condição passiva de expectador, sem muita iniciativa e "sem pensamento próprio", e passarem a ser protagonistas e autores de suas próprias histórias. Ou seja, "um jovem que em vez de esperar as coisas acontecerem, toma decisões, luta por seus direitos e faz acontecer", como ressalta o professor de Ciências Humanas.

No entendimento da professora de Participação Cidadã, o PLA é essencial na formação dos jovens de Mesquita, pois "desperta o jovem para uma participação ativa na comunidade, agindo coletivamente em busca da superação dos desafios encontrados na comunidade e na cidade onde vivem". Concepção semelhante possui a professora de Língua Portuguesa. Para ela, "através das ações comunitárias os jovens percebem que podem realmente mudar a realidade de sua comunidade".

Após meses de pesquisa nos problemas da comunidade, a precarização da garantia do direito à saúde foi considerada pelos jovens de uma escola como o principal desafio a ser enfrentado pelos moradores da comunidade. Assim, em parceria com a equipe da clínica da família local, as ações planejadas no PLA direcionaram-se para a oferta de serviços como: aferição de pressão de adultos, realização de palestras sobre prevenção de doenças cardiovasculares e sexualmente transmissíveis, além de atividades lúdicas para crianças referentes à saúde bucal. Na outra escola os jovens identificaram a problemática do recolhimento e acondicionamento do lixo como um dos grandes desafios vivido pelos moradores da comunidade vizinha, tendo sido elaboradas as seguintes ações: limpezas de rios e canais e realização de palestras em um espaço público da comunidade sobre educação socioambiental. Ao analisar os PLAs elaborados pelos jovens das duas unidades escolares, verifica-se uma análise superficial dos problemas vivenciados na comunidade. Não há o questionamento sobre as determinações da desigualdade social e o sistema de classes, produtos do sistema capitalista. Justificam os problemas vivenciados na comunidade como decorrentes da 
apatia e maus comportamentos dos moradores e/ou pela negligência dos governos e da classe política para com as condições de vida da população pobre, sem minimamente questionar as causas estruturais.

Na concepção da professora de Participação, responsável em ajudar os jovens a elaborarem o PLA, as ações desenvolvidas

estimulam o aluno a ser protagonista da sua vida e na comunidade em que mora; o faz compreender o porquê de participar na mudança de algo que não está bom no lugar em que mora. Através dessas ações o aluno constrói a ideia de que ele é responsável por sua comunidade (PROFESSORA DE PARTICIPAÇÃO CIDADÃ, 2016).

A professora salienta ainda que "a resolução dos problemas expressos nos PLAs depende de correlação de forças políticas e de burocracias governamentais que ultrapassam o período de execução do programa". Por essa razão, o êxito do plano não é aferido pela resolução da problemática inicial demandante da intervenção, mas "se a experiência possibilitou aos jovens perceberem a importância de se organizarem e trabalharem em grupo com vista à solução dos problemas de suas comunidades". O desafio de materializar o PLA é lançado nas mãos dos próprios jovens e converge com os propósitos da "Educação para o Desenvolvimento Sustentável" e com o que defende o Banco Mundial (2002, p.12), para quem "os pobres são os principais agentes da luta contra a pobreza". Esta ideia é absorvida de forma acrítica pelos educadores do PJU de Mesquita, que esperam depois da conclusão do programa que "os jovens carreguem para o cotidiano deles os aprendizados construídos nas aulas de Participação Cidadã e nas experiências do PLA; que coloquem em prática esses aprendizados com ações comunitárias dirigidas por eles".

As ações comunitárias estimuladas no PJU, orientadas com base na ideologia do capital social, possuem uma dimensão política enquanto estratégia de governabilidade e coesão social, e uma dimensão econômica, de educar os jovens da periferia para o associativismo colaboracionista na resolução de problemas relativos à vida coletiva, que venham incidir na redução da pobreza e na desigualdade social, agravadas pela retomada da ortodoxia da política macroeconômica neoliberal após o golpe jurídico, midiático e parlamentar de 2016. Segundo dados da PNAD-C (IBGE, 2017), o quantitativo de desempregados situa-se em torno de 12,7 milhões de brasileiros, sendo que entre 2014-2016 mais de 9 milhões de pessoas foram jogadas para baixo da linha de pobreza, totalizando 52,2 milhões de brasileiros (homens, mulheres e crianças) que vivem nessa condição, ocasionada pelo alto índice de desemprego. Nesse contexto de precarização extrema, os jovens de baixa escolaridade, pouca experiência profissional e moradores das regiões metropolitanas constituem as maiores vítimas do projeto político em execução.

Os resultados da pesquisa demonstram que o conteúdo político das ações comunitárias executadas é negligenciado, uma vez que os jovens não são estimulados a perceberem as determinações sócio-históricas da realidade cotidiana. $O$ educador perde a oportunidade de, na própria ação, na práxis, incitar os jovens à reflexão do processo histórico e das determinações objetivas e subjetivas dos problemas de diversas ordens 
BARBOSA, C. S

por eles vivenciados, de modo a criar condições para que novas ações possam ser geradoras de outras reflexões-ações que promovam a compreensão mais aprofundada a respeito dos problemas fundamentais da sua localidade e cidade. Como salienta Freire (1980), um processo de conscientização que possibilite uma melhor leitura do mundo para nele intervir.

O papel do professor é importante nesse processo, pois pode auxiliar os jovens a ultrapassar a aparência do fenômeno e desvelar o que à primeira vista não está explícito. Não problematizar as ações comunitárias dificulta a construção por parte dos jovens do que Gramsci (2007) chama de "consciência superior", a consciência crítica do (seu) mundo, da (sua) própria historicidade e de que faz parte de uma força social (consciência política) - passos importantes para a transformação social. Algumas mediações contribuem para a pouca reflexão em torno dessa perspectiva. A pouca atenção conferida à última etapa do PLA é uma delas, que consiste no momento da avaliação das ações planejadas/executadas. Com base no projeto pedagógico do programa, a última etapa do PLA reserva-se à avaliação e registro de todo processo percorrido. É o momento em que se busca conduzir os jovens a refletir sobre as principais dificuldades da participação de jovens na realização de ações coletivas; o sentido da participação cidadã sobre os direitos de cidadania dos jovens; as ações prioritárias de políticas públicas, programas ou projetos para a juventude na realidade em que vivem; além de solicitar sugestões que promovam continuidade à atuação social e à participação dos jovens em ações coletivas de interesse público.

A carga horária reduzida destinada às aulas de Participação Cidadã (1 hora semanal) é outra mediação a ser considerada, não obstante é justificada pelos elaboradores do programa de que o compromisso com a formação para cidadania pertence a todas as disciplinas, não se restringindo à Participação Cidadã. No entanto, a questão é: como os professores pesquisados podem formar os jovens para a participação política e social nos distintos espaços da cidade, se eles também não exercem sua cidadania plena e ativa, de tal modo que não participam de alguma instituição e/ou organização social de interesse coletivo, e não possuem uma reflexão aprofundada a respeito de questões referentes à cidadania e à política para além das mensagens divulgadas na grande mídia? Como os professores podem oferecer aquilo que não têm para dar?

Pelo exposto, as concepções dos professores sobre o PLA e a forma com que as ações comunitárias são conduzidas no ProJovem Urbano da cidade de Mesquita fortalecem o sentido da "união dos esforços" para a resolução dos problemas - local e regionalmente -, a fim de impedir que o agravamento da precarização das condições de reprodução da existência das classes trabalhadoras e os problemas sociais dela decorrentes não ultrapassem o patamar sustentável e venham a atrapalhar o processo de acumulação dos detentores do grande capital.

\section{CONSIDERAÇÕES FINAIS}

A participação social pode contribuir de maneira decisiva no processo formativo do jovem, uma vez que potencializa a formação de valores e de atitudes cidadãs. No entanto, no ProJovem Urbano do município de Mesquita não há interesse por parte da 
maioria dos agentes envolvidos para o alcance desse objetivo; principalmente os gestores municipais que não criam as condições estruturais necessárias para estimular a participação dos jovens na macropolítica e para a construção da cidadania ativa. Esse também não é o sentido conferido à participação nos relatórios das agências multilaterais quando orientam que "o governo precisa investir nas pessoas de baixa renda e empoderá-las". Afinal, como bem questiona Katz (2010), estariam as classes dominantes do capitalismo dispostas a admitir pacificamente a soberania popular, o protagonismo da cidadania e a efetiva participação política dos jovens em detrimento da delegação/representação, o que é incompatível com a preservação de seus privilégios? Fernandes também não acredita nessa possibilidade:

Os estratos dominantes das classes possuidoras nunca permitirão que a revolução democrática atinja uma tal magnitude que as classes trabalhadoras possam usar seu espaço político dentro da sociedade civil para converter a participação popular em um fato histórico de eliminação das causas e efeitos dos antagonismos de classe. Acreditar nisso seria o mesmo que ressuscitar o socialismo utópico ou que admitir que a reforma pode ir tão longe, dentro da ordem (FERNANDES, 2008, p. 56).

O privilegiamento conferido a ações locais/comunitárias nos relatórios das agências multilaterais faz parte das estratégias da nova pedagogia da hegemonia para conformação dos sujeitos a uma prática política, na qual predomina a pequena política em detrimento da grande política (NEVES, 2005). Sendo assim, Boron (2010, p. 84) questiona:

Até que ponto é realista concebermos a existência e postularmos a necessidade de uma democracia de "alta intensidade", protagonista ou participativa, sem estabelecermos as condições necessárias para sua materialização efetiva no espaço do Estado nacional?

Segundo Boron (2010), um modelo participativo só é tolerável por parte da burguesia no plano local (ainda que com resistências), pois para a cultura política dominante das chamadas democracias latino-americanas a política é um assunto para as elites e não para os povos. Desse modo, estando o ProJovem Urbano estruturado para execução do papel atribuído à educação no novo milênio, com base no alinhamento entre seus objetivos, matriz curricular e as orientações presentes nos relatórios das agências multilaterais destinados aos países em desenvolvimento, concluímos que a intencionalidade das ações comunitárias estimuladas no programa não é orientada para o fortalecimento da cidadania plena dos jovens por meio da participação política nos espaços decisivos e decisórios, mas sim para a produção de capital social como estratégia importante para redução da pobreza e da desigualdade social. Visa a estimular a união dos esforços entre os membros da comunidade com vista à resolução dos problemas locais sem esperar pela ação do Estado. Para isso, faz-se necessário desenvolver nas pessoas os hábitos de cooperação e solidariedade; valores melhores 
BARBOSA, C. S

desenvolvidos por meio das experiências associativas, nas quais a educação tem um importante papel a cumprir. Não seria esta a direção ético-política da Participação Social?

Por fim, a partir da compreensão ampliada da pobreza, "como a incapacidade de alcançar os padrões básicos em nutrição, saúde, educação, meio ambiente e participação" (BANCO MUNDIAL, 2000, p. 12), pode-se dizer que os PLAS desenvolvidos pelos jovens de Mesquita, cujas temáticas foram saúde e meio ambiente, são processos formativos requeridos pela educação para o desenvolvimento sustentável, sobretudo se operamos com a compreensão ampliada de desenvolvimento, que desde 2002, na Conferência de Joanesburgo, passou a abranger justiça social e luta contra a pobreza.

Artigo recebido em: 01/11/2018

Aprovado para publicação em: 15/01/2019

\section{PROJOVEM URBANO: EDUCATIONAL STRATEGY FOR POVERTY REDUCTION IN GOVERNMENTS} LULA DA SILVA AND DILMA ROUSSEF?

ABSTRACT: The article aims to analyze the alignment of community actions stimulated in the Urban ProJovem (PJU) to the role attributed to education in the new millennium, to produce social capital as a strategy to reduce poverty and social inequalities. The documentary-empirical research was developed in the city of Mesquita / RJ and based on historical-critical thinking. Based on the analysis of the reports of the multilateral agencies, observation of the classes and interviews with teachers, the PJU concludes that the PJU is a governance strategy, serving the "administration" of poverty. Without much political exploration of community action, teachers eventually strengthen the "unity of efforts" so that social problems remain at a sustainable level and do not disturb the interests of big capital.

KEYWORDS: ProJovem Urbano. Poverty. Share capital. Young.

PROJOVEM URBANO: ESTRATEGIA EDUCACIONAL PARA LA REDUCCIÓN DE LA POBREZA EN LOS GOBIERNOS LULA DE SILVA Y DILMA ROUSSEF?

RESUMEN: El artículo pretende analizar la alineación de las acciones comunitarias estimuladas en el ProJovem Urbano (PJU) al papel atribuido a la educación en el nuevo milenio, el de producir capital social como estrategia para la reducción de la pobreza y las desigualdades sociales. La investigación documental-empírica fue desarrollada en el municipio de Mesquita/RJ y fundamentada en el pensamiento histórico-crítico. Con base en el análisis de los informes de las agencias multilaterales, observación de las clases y entrevistas realizadas con profesores, concluye que el PJU se configura como estrategia de gobernabilidad, al servicio de la "administración" de la pobreza. Sin mucho explotar políticamente las acciones comunitarias, los profesores acaban por fortalecer la "unión de los esfuerzos" para que los problemas sociales se mantengan en el nivel sostenido y no obstaculicen los intereses del gran capital.

PALABRAS CLAVE: ProJovem Urbano. Pobreza. Capital social. Juventud. 


\section{REFERÊNCIAS}

BANCO MUNDIAL (BIRD). Desenvolvimento e redução da pobreza: reflexão e perspectiva. Outubro, 2004.

BANCO MUNDIAL. Luta contra a pobreza: relatório sobre o Desenvolvimento Mundial 2000/2001. Washington, 2000.

BRAGA, R. A política do preconceito: do populismo à hegemonia lulista. São Paulo: Boitempo: USP, Programa de pós-graduação em Sociologia, 2012.

BRASIL. Manual do educador: Orientações Gerais. ProJovem Urbano. Brasília, 2008.

BRASIL. Política Nacional de Assistência Social (PNAS). Ministério do Desenvolvimento Social e Combate a Fome, Brasília, 2004.

BRESSER-PEREIRA, L. C. O novo desenvolvimentismo e a ortodoxia convencional. São Paulo em Perspectiva, v.20, n.3, p.5-24, jul./set. 2006.

BORON, A. Crise das democracias e os movimentos sociais nas América Latina: notas para uma discussão. In: CASTELO, R. (Org.). Encruzilhadas da América Latina no Século $X X$. Rio de Janeiro: Pão e Rosas, 2010. p. 81-97.

CASTELO, R. O novo desenvolvimentismo e a decadência ideológica do estruturalismo latino-americano. In: CASTELO, R. (Org.). Encruzilhadas da América Latina no Século XX. Rio de Janeiro: Pão e Rosas, 2010. p. 191-211.

COLEMAN, J. Social Capital in the Creation of Human Capital. American Journal of Sociology, v. 94, Supplement, p. S95-S120, 1988.

COMISSÃO ECONÔMICA PARA A AMÉRICA LATINA E O CARIBE (CEPAL). Juventude, plobación y desarrollo em América Latina y el Caribe. Problemas, oportunidades y desafios. Santiago, Chile, 2000.

COMISSÃO ECONÔMICA PARA A AMÉRICA LATINA E O CARIBE (CEPAL). Coesão Social: inclusão e sentido de pertencer na América Latina e no Caribe (Síntese). Chile, maio 2007.

FERNANDES, F. A Revolução burguesa no Brasil: ensaio de interpretação sociológica. 5. ed. São Paulo: Globo, 2008.

FERNANDES. Capitalismo dependente e classes sociais na América Latina. 2. ed. Rio de 
BARBOSA, C. S

Janeiro: Zahar, 1975.

FÉRES, M. J. V. ProJovem Urbano: gestão e desafios. In: FÉRES, M. J. V. et al. (Org.). Textos complementares para a formação de gestores. Brasília: ProJovem Urbano, 2008.

FREIRE, P. Conscientização: teoria e prática da libertação; uma introdução ao pensamento de Paulo Freire. 3. ed. São Paulo: Editora Moraes, 1980.

FUKUYAMA, F. Construção de Estados: governo e organização no século XXI. Rio de Janeiro: Rocco, 2005.

GIDDENS, A. A terceira via: reflexões sobre o impasse político atual e o futuro da socialdemocracia. 5. ed. Rio de Janeiro/RJ: Record, 2005.

GRAMSCl, A. Cadernos do Cárcere. Edição e tradução Carlos Nelson Coutinho; co-edição Luiz Sergio Henriques e Marco Aurélio Nogueira. 4. ed. Rio de Janeiro: Civilização Brasileira, 2007. (v. 3).

INSTITUTO BRASILEIRO DE GEOGRAFIA E ESTATÍ́STICA. Pesquisa Nacional por Amostra de Domicílios, PNAD. Síntese dos indicadores de 2016. Brasília, 2017.

KATZ, C. Socialismo ou novo-desenvolvimentismo? In: CASTELO, R. (Org.). Encruzilhadas da América Latina no Século XX. Rio de Janeiro: Pão e Rosas, 2010.

KLIKSBERG, B. Repensando o Estado para o desenvolvimento social: superando dogmas e convencionalismos. São Paulo: Cortez, 1998. p. 57-80.

KLIKSBERG, B. Falácias e Mitos do desenvolvimento social. 2. ed. São Paulo/SP: Cortez; Brasília/DF: UNESCO, 2003.

MARTORANO, L. C. Conselhos e democracias. em busca da participação e da socialização. São Paulo: Editora Expressão Popular, 2011.

NEVES, L. M. W. A nova pedagogia da hegemonia: estratégias da burguesia para educar o consenso na atualidade. São Paulo: Xamã, 2005.

PUTNAM, R. D. Comunidade e Democracia: a experiência da Itália moderna. 3. ed. Rio de Janeiro/RJ: FGV, 2002.

UNESCO. Década da educação das nações unidas para o desenvolvimento sustentável 2005-2014. Documento Final do Plano Internacional de Implementação. Brasília: OREALC; Unesco, 2005. 
Carlos Soares Barbosa: Doutor em Políticas Públicas e Formação Humana (UERJ). Professor Adjunto da Faculdade de Educação/UERJ-Campus Maracanã, Departamento de Educação Inclusiva e Continuada. Pesquisador das áreas de Trabalho e Educação e da Educação de Jovens e Adultos (EJA).

ORCID: https://orcid.org/0000-0003-4519-5174

E-mail: profcarlossoares@smail.com

Este periódico utiliza a licença Creative Commons Attribution 3. 0, para periódicos de acesso aberto (Open Archives Iniciative - OAI). 